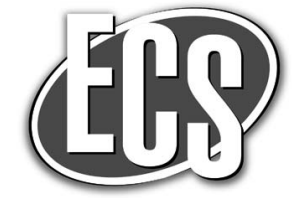

\title{
Aluminum Anodization in Deionized Water as Electrolyte
}

\author{
Aleksey D. Lisenkov, ${ }^{\text {a,*,z }}$ Sergey K. Poznyak, ${ }^{b}$ Mikhail L. Zheludkevich, ${ }^{\text {a,c }}$ \\ and Mário G. S. Ferreira ${ }^{a}, * *$ \\ ${ }^{a}$ Department of Materials and Ceramics Engineering/CICECO, University of Aveiro, 3810-193 Aveiro, Portugal \\ ${ }^{b}$ Institute for Physical Chemical Problems, Belarusian State University, 220050 Minsk, Belarus \\ ${ }^{c}$ Institute of Materials Research, Helmholtz-Zentrum Geesthacht, 21502 Geesthacht, Germany
}

\begin{abstract}
Thin oxide films were prepared electrochemically on the aluminum surface using the high-voltage discharge and potentiostatic methods in deionized water as an electrolyte. The growth of continuous films occurred only at potentials lower than the breakdown potential. The films obtained by the discharge method are more uniform and can grow to a higher thickness in comparison to those formed by the potentiostatic mode, as demonstrated by electrochemical impedance spectroscopy (EIS), transmission electron microscopy (TEM), and scanning Kelvin probe force microscopy (SKPFM). The data herein obtained can be used as a reference to understand better the properties of the films produced in conventional electrolytes where apart from water other species are present. (C) The Author(s) 2016. Published by ECS. This is an open access article distributed under the terms of the Creative Commons Attribution Non-Commercial No Derivatives 4.0 License (CC BY-NC-ND, http://creativecommons.org/licenses/by-nc-nd/4.0/), which permits non-commercial reuse, distribution, and reproduction in any medium, provided the original work is not changed in any way and is properly cited. For permission for commercial reuse, please email: oa@electrochem.org. [DOI: 10.1149/2.0881607jes] All rights reserved.
\end{abstract}

Manuscript submitted January 29, 2016; revised manuscript received April 11, 2016. Published April 21, 2016.

Anodizing treatment is widely used on aluminum and its alloys in industrial practice to enhance surface performance (corrosion resistance, hardness and wear resistance) and to modify physical and chemical properties of the metal surface. ${ }^{1,2}$ Anodization is a convenient and important method of oxide film formation owing to low cost, flexibility and easiness. ${ }^{3-7}$ There are several anodization processes that are currently used: conventional anodic oxidation (potentiostatic or galvanostatic) and plasma electrolytic oxidation (PEO). ${ }^{3-5,7}$ The conventional anodization is well studied and allows growing oxide films of controlled thickness and quality., 5 The films can be partially hydrated. ${ }^{5}$ The other method, PEO, which utilizes potentials above the breakdown voltage of the oxide film growing on the anode surface, makes possible to prepare well adherent, hard, ceramic-like coatings. ${ }^{3,4}$ Both methods are currently applied in industry although they are still under investigation. One of the problems, which appears when studying the anodic oxides, is related to the impossibility of preparing a pure oxide film without foreign atoms apart from metal atoms of the substrate, oxygen and hydrogen atoms. In all electrolytes used for anodization, different ionic species are added to increase the conductivity of solution and the foreign atoms are trapped into the growing oxide. ${ }^{8}$ According to the literature, the concentration of the foreign atoms during anodic oxidation usually does not exceed $1 \%,{ }^{9}$ however, impact of them on anodic film parameters, such as concentration of ionized donors, conductivity and photosensitivity, is significant. It was shown that the electrolyte concentration used for anodization influences the dopant content in the oxide ${ }^{8}$ and even small amount of ionic species in solution results in changes of the film properties. Thus, in order to have a reference point for further research it is important to obtain an oxide film with minimal influence of foreign atoms. One of the electrolytes that can help to decrease the amount of entrapped foreign atoms in the oxide is anodization in hydroxide solutions. Although the concentration of extraneous elements is lower than the elements entrapped from the conventional electrolytes (such as ammonium pentaborate), even in this case foreign cations will be entrapped to the bulk of the film. Of course, impurity-free oxide on the metal surface can be prepared by other methods, such as oxidation in oxygen atmosphere at high temperature ${ }^{1}$ or in boiling water, ${ }^{10}$ but the properties of the obtained films will be different of those prepared by electrochemical oxidation. This motivates the present work where only deionized water was used as an electrolyte.

The properties of the films obtained in the present work were studied by scanning (SEM) and transmission electron microscopies

\footnotetext{
*Electrochemical Society Student Member.

**Electrochemical Society Member.

zE-mail: lisenkov@ua.pt
}

(TEM), electrochemical impedance spectroscopy (EIS) and scanning Kelvin probe force microscopy (SKPFM). SKPFM allows simultaneous mapping of topography and Volta potential distribution on passive surfaces in air. ${ }^{11,12}$ The Kelvin probe methods are based on measurement of Volta potential difference (VPD) between a surface and a reference electrode. Several factors can influence the Volta potential measurements, i.e. composition and structure of the oxide film covering the aluminum surface and intermetallics, tip-sample distance and adsorption of different molecules at the surface. Previously it was shown ${ }^{10,13}$ that the VPD distribution observed on some metal surfaces correlates, for example, with their corrosion properties.

The main aim of the present work is to demonstrate the possibility of preparing impurity-free anodic oxide films on valve metals, particularly aluminum, by high-voltage anodization in deionized water. The current paper is the first part of a research focused on the preparation of impurity-free oxides by electrochemical methods.

\section{Experimental}

The electrochemical cell used for anodization consisted of an aluminum (Alfa Aesar, 99.999\%) anode with a working surface of $4 \mathrm{~cm}^{2}$ and Ti cathode (Alfa Aesar, 99.7\%) with about 20 times larger surface area. Titanium was chosen as a cathode material due to its high mechanical strength and chemical inertness. The electrodes were abraded using abrasive papers up to grit 4000 . Then the Ti electrode was chemically polished in a $\mathrm{HF}: \mathrm{HNO}_{3}(1: 3$ by volume) mixture. Aluminum was electrochemically polished in $\mathrm{C}_{2} \mathrm{H}_{5} \mathrm{OH}: \mathrm{HClO}_{4}$ (4:1 by volume) electrolyte in potentiostatic regime at $20 \mathrm{~V}$ to a mirror finish. After polishing, both electrodes were thoroughly rinsed with deionized water.

Deionized water $\left(18 \times 10^{6} \Omega \cdot \mathrm{cm}\right)$ prepared from distilled water was used as an electrolyte for $\mathrm{Al}$ anodization. Preparation of the oxide film on $\mathrm{Al}$ was performed by two different ways: potentiostatic and high-voltage discharge methods. In the former, a constant voltage in the range from 1000 to $2000 \mathrm{~V}$ with $200 \mathrm{~V}$ step was applied to the electrodes using a Matsusada AU-3P400 high voltage power supply, and anodization was performed for different time intervals. The discharge method was another technique, in which a low-inductance $100-\mu \mathrm{F}$ capacitor bank, with a measured internal resistance of $2.2 \times$ $10^{3} \Omega$, charged to the same voltages as in the potentiostatic mode, was then discharged to the cell. In order to prepare films with different thicknesses, the capacitor was discharged sequentially through the electrochemical cell between 1 and 30 times to the residual voltage of $100 \mathrm{~V}$. The length of discharge varied in the range of 200-350 s depending on the film thickness. The thickness of the oxide film was controlled by two parameters: initial voltage and number of 
discharges. In both methods, the resistance of the electrolyte plays a very important role. During anodization, the resistance of deionized water decreases from $8 \times 10^{5} \Omega$ to $1 \times 10^{5} \Omega$, which could affect significantly the process. The electrolyte was replaced by fresh portions and all electrodes were carefully rinsed with deionized water after each two discharges or if the resistance of the water in the electrochemical cell, measured at the frequency of $1000 \mathrm{~Hz}$, became lower than 6 $\times 10^{5} \Omega$. To compare the properties of the obtained anodic oxides, anodization of $\mathrm{Al}$ was also performed in galvanostatic mode at a currant density of $10 \mathrm{~mA} / \mathrm{cm}^{2}$ followed by potentiostatic anodization in a $0.1 \mathrm{M}$ ammonium pentaborate $\left(\left(\mathrm{NH}_{4}\right)_{2} \mathrm{~B}_{10} \mathrm{O}_{16}\right)$ aqueous solution.

Determination of the potential distribution in the electrolyte plays an important role for this work. Theoretically, the potential drop can be estimated by dividing the applied potential by the distance between electrodes, but several parameters, such as potential drop on the electrode surfaces, edge effects and nonuniformity of the electrolyte will result in significant error. A better way is the measurement of the potential between the counter electrode and a neutral point in the electrolyte. In this case it is possible to determine non-uniformities of the electrolyte conductivity and avoid errors connected with processes on the electrode (the current between the counter electrode and tip is negligible). However, in this case the geometry plays a role (flat electrode vs. point tip), thus modelling and calculations become difficult. To avoid this problem two electrodes with platinum tips $(10 \mu \mathrm{m}$ in diameter) were placed in the electrolyte bulk between the cathode and the anode. In this case the geometry is not relevant (point tip vs. point tip). The distance between tips can be varied, and they can be placed in different parts of the electrolyte bulk to determine the field distribution. To determine the potential at the electrode surface, $\mathrm{E}$, the cell geometry was taken as two parallel electrodes in highresistance electrolyte. Over the main part of the surface the potential distribution is uniform. Due to the high resistivity of the electrolyte, the influence of the volume and distance to the walls of the cell can be ignored.

In highly resistive electrolytes, like deionized water, the anodic film thickness cannot be estimated by the applied voltage or by the charge passed through the cell during the discharge as in the case of the traditional anodization. Electrochemical impedance spectroscopy (EIS) is an effective tool to estimate the thickness of oxide films as well as to obtain information about their structure, for example, crystallinity and defects. In the present work, the thickness of the alumina films was evaluated using EIS measurements and confirmed by TEM. For the sake of comparison, thickness of the oxide was also estimated for the discharge-prepared films from the voltage vs time plots.

The EIS measurements were performed using a Gamry FAS2 Femtostat with a PCI4 Controller in a frequency range from $10^{5}$ to $10^{-2}$ $\mathrm{Hz}$ with 7 points per decade. The measurements were carried out at room temperature in a conventional three-electrode cell consisting of a mercury-mercurous sulfate reference electrode, a cylindrical platinum foil as a counter electrode and the working electrode with an exposed area of $1 \mathrm{~cm}^{2}$. Impedance spectra were recorded by applying a $10 \mathrm{mV}$ (RMS) sinusoidal perturbation at the open circuit potential. The cell was placed in a Faraday cage to avoid interferences with external electromagnetic fields. A $0.1 \mathrm{M}$ ammonium pentaborate solution was used as the electrolyte for EIS measurements. At least five samples prepared in the same conditions were tested to ensure reproducibility of the results. The impedance plots were fitted using equivalent circuits by means of the Echem Analyst software from Gamry Inc.

Transmission electron microscopy (TEM) was carried out using a Hitachi $\mathrm{H} 9000$ microscope at an acceleration voltage of $300 \mathrm{kV}$. Electron transparent sections of the samples for TEM were cut with a Leica Reichert Supernova ultramicrotome. Investigation of the surface topography was performed using a Hitachi SU-70 SEM.

A Digital Instruments Nanoscope III atomic force microscope with conductive Pt-Cr probes (AppNANO) was used for SKPFM measurements. The obtained VPD values are presented versus the VPD measured for pure $\mathrm{Ni}$ as a reference.

\section{Results and Discussion}

The results of $\mathrm{Al}$ anodization in deionized water under high-voltage potentiostatic and discharge modes with applied voltages between 1000 and $2000 \mathrm{~V}$ (Table I) showed that up to $1600 \mathrm{~V}$ in both cases oxide films with different properties can be obtained. For the first method the film thickness ranged from 5 to $12 \mathrm{~nm}$ (lower values are for lower voltages). Between 1000 and $1600 \mathrm{~V}$ the film was found to be uniform if anodization was performed during 1-2 minutes depending on the applied potential (Table I). In the case of the lower voltage range (1000-1200 V) it was possible to generate films up to 2 minutes of anodization. However, anodization for a period less than 1 minute resulted in formation of thin films, which thickness was comparable with natural oxide. In the case of the higher voltages (1400-1600 V) anodization was performed for 1 or 1.5 minute. The film thickness is limited by two parameters: the thickness of the natural oxide from the lower side and the breakdown of the film from the higher one. Longer anodization of the electrodes resulted in breakdown of the films. Application of potentials of 1800 and $2000 \mathrm{~V}$ in the potentiostatic method also resulted in breakdown of the film (Fig. 1A). For the discharge method, the film thickness was between 9 and $11 \mathrm{~nm}$ after 20 discharges and between 14 and $16 \mathrm{~nm}$ after 30 discharges for $\mathrm{U}=1000-1200 \mathrm{~V}$. When the voltage increased up to 1400-1600 $\mathrm{V}$, the thickness rose to $15 \mathrm{~nm}$ after 10 discharges and $26 \mathrm{~nm}$ after 20 discharges. Under discharge mode the film still grew at $1800 \mathrm{~V}$,

Table I. Anodic film thickness, applied potential at the electrode after correcting for the ohmic drop in solution (E) and oxide growth parameters for aluminum anodized in deionized water at different applied voltages.

Potentiostatic method

\begin{tabular}{|c|c|c|c|}
\hline $\mathrm{U}_{0} / \mathrm{V}$ & Time, $\min$. & Thickness, nm & Number of discharge \\
\hline 1000 & 2 & $5 \pm 3$ & $\begin{array}{l}20 \\
30\end{array}$ \\
\hline 1200 & 2 & $6 \pm 2$ & $\begin{array}{l}20 \\
30\end{array}$ \\
\hline 1400 & 1,5 & $9 \pm 4$ & $\begin{array}{l}10 \\
20\end{array}$ \\
\hline 1600 & 1 & $12 \pm 4$ & $\begin{array}{l}10 \\
20\end{array}$ \\
\hline 1800 & - & $\begin{array}{l}\text { Breakdown occurs from the } \\
\text { beginning of the process. }\end{array}$ & $5-7$ \\
\hline 2000 & - & $\begin{array}{l}\text { Breakdown occurs from the } \\
\text { beginning of the process. }\end{array}$ & - \\
\hline
\end{tabular}

Discharge method

\begin{tabular}{|c|c|c|}
\hline Thickness, nm & Parameter $\beta \times 10^{-2}$ & $\mathrm{E} / \mathrm{V}$ \\
\hline $\begin{array}{l}9 \pm 3 \\
14 \pm 4\end{array}$ & 5,8 & 62 \\
\hline $\begin{array}{l}11 \pm 3 \\
16 \pm 4\end{array}$ & 5,3 & 75 \\
\hline $\begin{array}{l}14 \pm 2 \\
24 \pm 2\end{array}$ & 4,6 & 88 \\
\hline $\begin{array}{l}15 \pm 2 \\
26 \pm 2\end{array}$ & 4,4 & 100 \\
\hline $16 \pm 2$ & 4,9 & 115 \\
\hline $\begin{array}{l}\text { Breakdown occurs } \\
\text { after the first } \\
\text { discharge. }\end{array}$ & & 130 \\
\hline
\end{tabular}




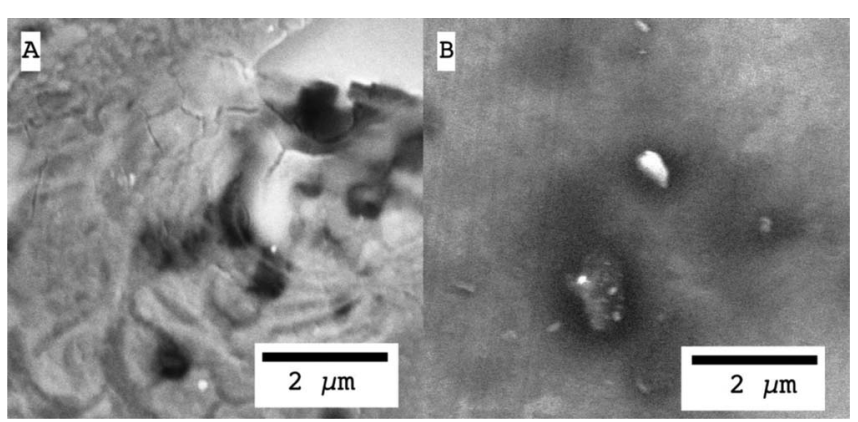

Figure 1. SEM images of the film breakdown on the oxides prepared at applied voltage of $2000 \mathrm{~V}$ by the potentiostatic (A) and discharged (B) methods.

reaching a maximum thickness of $16 \mathrm{~nm}$ after 5-7 discharges. At $2000 \mathrm{~V}$ the oxide film cannot be prepared by either methods, since breakdown occurred (Fig 1B). It should be noted, that in the case of the high-voltage potentiostatic method, the results show very poor reproducibility of breakdown events: even small fluctuations of parameters such as resistivity and amount of gases (oxygen and nitrogen) in the electrolyte, preparation and purity of the electrode surface can influence the process.

In contrast to the high-voltage discharge anodization in highly conductive electrolytes, ${ }^{14-16}$ the process in deionized water cannot be explained by the same mechanism and has a significant difference in duration. As it was shown previously ${ }^{15}$ in highly conductive electrolytes, such as $0.1 \mathrm{M}$ ammonium pentaborate, the full discharge takes less than $0.5 \mathrm{~s}$. In deionized water the applied voltage decays down to $100 \mathrm{~V}$ over a period of more than $100 \mathrm{~s}$ (Fig. 2). In deionized water, the measurements do not reveal the presence of plasma since besides the time elapsed, the current is low compared to previous works. ${ }^{8,15}$ This is due to a large potential drop in the electrolyte bulk. In the conventional electrolyte, a plasma layer is formed on the anode surface and the oxide growth occurs in this layer. ${ }^{8,15}$ Taking into account the growth rate of the films, their composition and structure, it can be suggested that the growth mechanism is similar to that obtained in potentiostatic method in conventional solutions where plasma is not similarly formed during film growth. ${ }^{10}$

In highly conductive solutions such as potassium hydroxide, an increase of the voltage to values higher than $100 \mathrm{~V}$ usually results in the formation of oxide film by PEO process, where a breakdown of the oxide followed by formation of plasma discharges and rapid growth of the porous anodic film occurs. However, in deionized water due to its high resistivity, no faradaic processes take place up to voltages of $1000 \mathrm{~V}$. Further increment of the voltage to higher values leads to the formation of a thin oxide film. The growth of the oxide under such conditions is limited to the range of $1000 \mathrm{kV}-1800 \mathrm{kV}$ (Table I). At a certain voltage applied to the electrode, breakdown occurs only when a certain thickness of the oxide is reached. The same happens if the film is thick enough, but the voltage is lower than that required for filament formation (this voltage is the border between conventional anodization and PEO). In the case of potentiostatic oxidation, a constant potential is applied to the electrode, resulting in breakdown of the oxide when the thickness is enough (critical thickness) for the filament formation. Thus the thickness of the oxide is a limiting factor for dense oxide growth in high voltage anodization.

Electron microscopy (TEM and SEM) examination of the Al samples anodized by the potentiostatic method demonstrates a nonuniform oxide thickness distribution across the electrode surface (Figs. $3 \mathrm{~A}, 3 \mathrm{C}$ ). However, the films prepared by the high-voltage discharge method were found to be more uniform, without defects and fluctuations of the thickness (Figs. 3B, 3D). The oxide structure in the latter case is similar to the films previously prepared by powerful pulsed oxidation in ammonium pentaborate. ${ }^{15}$

SKPFM measurements (Fig. 4A) on the Al surfaces treated in deionized water by potentiostatic oxidation demonstrate nonuniform charge distribution on the surface: the Volta potential changed across the film, rising in the most defected zones (up to $+10 \mathrm{mV}$ vs. Ni) and decreasing in the intact areas (down to $-9.7 \mathrm{mV}$ vs. Ni). These results are a consequence of the nonuniform thickness of the oxide in the different areas. ${ }^{10,15}$ It was also observed that applying a constant high voltage to the electrochemical cell with deionized water (for periods longer than 1-2 $\mathrm{min}$ ) led to the appearance of breakdown processes on the surface.

In contrast to the case of potentiostatically prepared samples, SKPFM studies of the discharge prepared ones (Fig. 4B) showed low fluctuation of the Volta potential. Furthermore, the surface potential rose as the oxide film thickness increased (Fig. 4C), which is in a good agreement with the observations reported previously. ${ }^{10} \mathrm{In}$ the case of this method, as the voltage was applied through discharge of a capacitor, the conditions for film breakdown were not met. The voltage applied to the electrodes was lower than the minimum needed for breakdown of the oxide film. Thus, the pulse method seems to be effective for preparing impurity free thin anodic oxide films in highly resistive electrolytes.

The current flowing through an electrode depends on the total overpotential, $\eta$, which can be divided ${ }^{17}$ in the following components:

$$
\eta=\eta_{\text {res }}+\eta_{\text {conc }}+\eta_{\text {act }}
$$

where $\eta_{\text {res }}$ describes the resistance overpotential resulting from the ohmic drop in the bulk of the electrolyte, $\eta_{\text {conc }}$ is the concentration overpotential which is related to mass transfer and $\eta_{\text {act }}$ is the activation overpotential. Due to the high resistivity of deionized water, the overpotential $\eta_{\text {res }}$ should be significantly higher in comparison to the conventional electrolytes. In order to estimate the $\eta_{\text {res }}$ value, two platinum tips were placed in the middle part of the cell and the
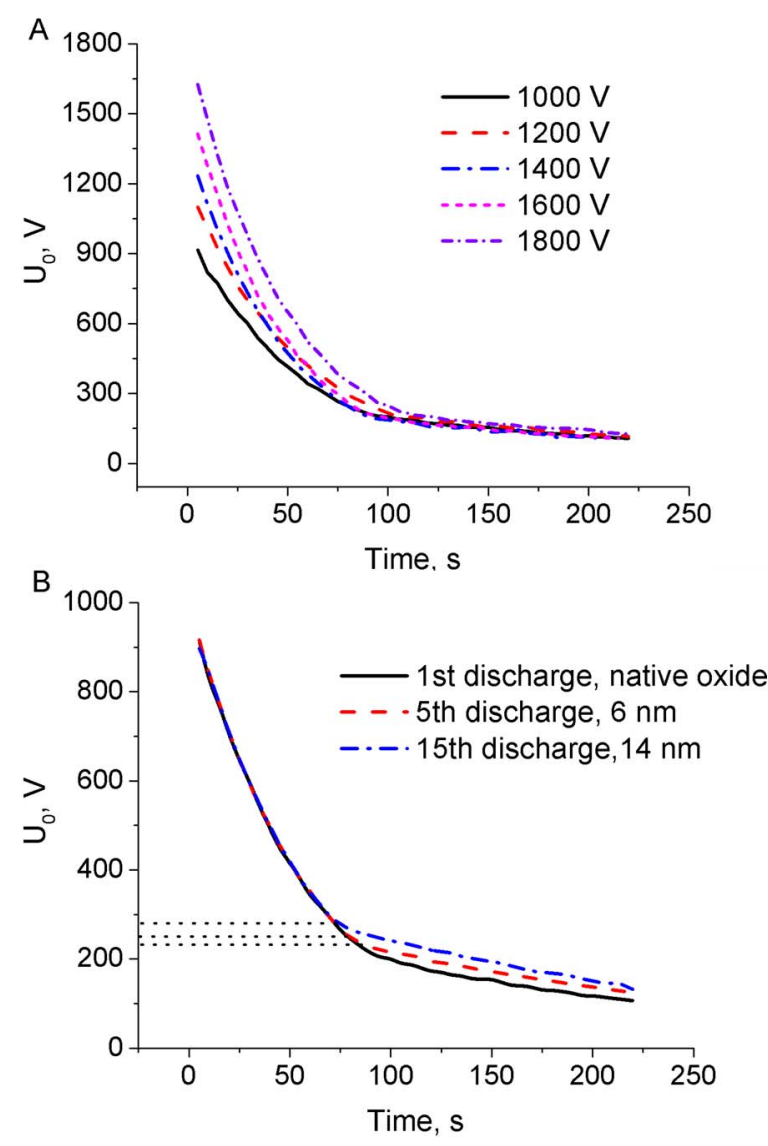

Figure 2. (A) Discharge plots for the aluminum anodization by discharge method at different potentials applied to the Al electrodes. (B) Discharge plots for the aluminum anodization by discharge method at $1000 \mathrm{~V}$ applied to the electrode covered with oxide film with different thicknesses. 


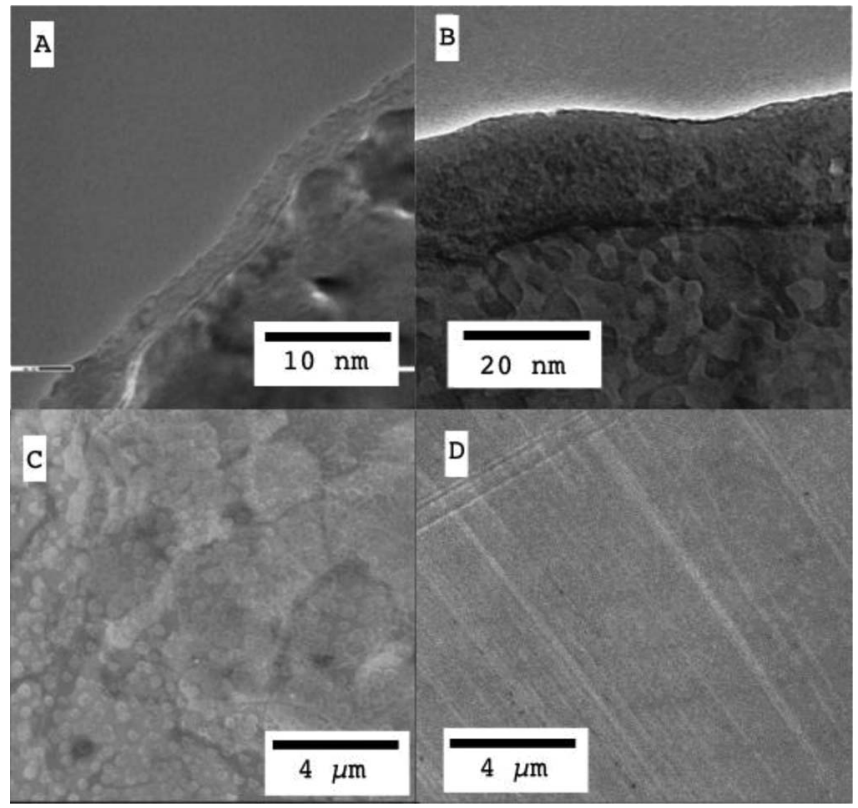

Figure 3. TEM cross sectional images (A, B) and SEM images (C, D) of aluminum oxide prepared by high-voltage potentiostatic $(\mathrm{A}, \mathrm{C})$ and discharge (B, D) methods

voltage between them was measured. The distribution of the field in the bulk of the electrolyte was found to be uniform. The voltage available for the electrochemical process at the electrode for the initial voltage (time $=0$ ):

$$
E=U-\eta_{\text {res }}
$$

can thus be estimated for the different applied potentials (Table I).

During the film growth some ions can be injected from the electrode into deionized water (even in small amount), resulting in local fluctuations of the solution resistance. In such regions, the electrode potential can change. The film growth occurs preferentially in these areas and the amount of charge used for the oxide film growth on the rest of the surface will be lower. In the case of the discharge method, the electrolyte can homogenize and the layer near the electrode can be restored due to the diffusion process between the discharges, resulting in more uniform film growth (Fig. 3).

To understand better the processes, that occur during the discharge anodization, the temporal evolution of the applied voltage was recorded (Figs. 2A, 2B). It was found that the discharge plot consisted of two parts, both of which can be described by the equation of capacitor discharge ${ }^{20}$ but with different resistance parameters:

$$
U_{t}=U_{0}\left(e^{-\frac{t}{\beta C}}\right)
$$

where $U_{t}$ is the voltage after the time (s), $t$, from the beginning of the discharge, $U_{0}$ is the initial applied voltage, $C$ is the capacitance and $\beta$ is the resistance parameter. Both parts of the plots can be easily separated (Figs. 2A, 2B); the first part is highly influenced by the applied voltage and does not change with the oxide thickness, while the second part is displaced positively with the film thickness. Fitting the first part of the plots obtained at different applied voltages (Fig. 2A) using Equation 3 , the parameter $\beta$ can be estimated (Table I). In the second part, the faradaic process related to the oxide growth does not take place. The resistance between electrodes becomes significantly higher than the internal resistance of the capacitor and the only process that takes place, is self-discharge of the capacitor. Thus the film growth occurs only during the first period of the discharge and only depends on the initial voltage applied. The change in the voltage $U_{0}$ in the second part of the plot is linearly related to the thickness of the oxide formed. Thus it is possible to estimate the thickness of the film using the value of $U_{0}$ obtained from the fitting of this section of the discharge plot.
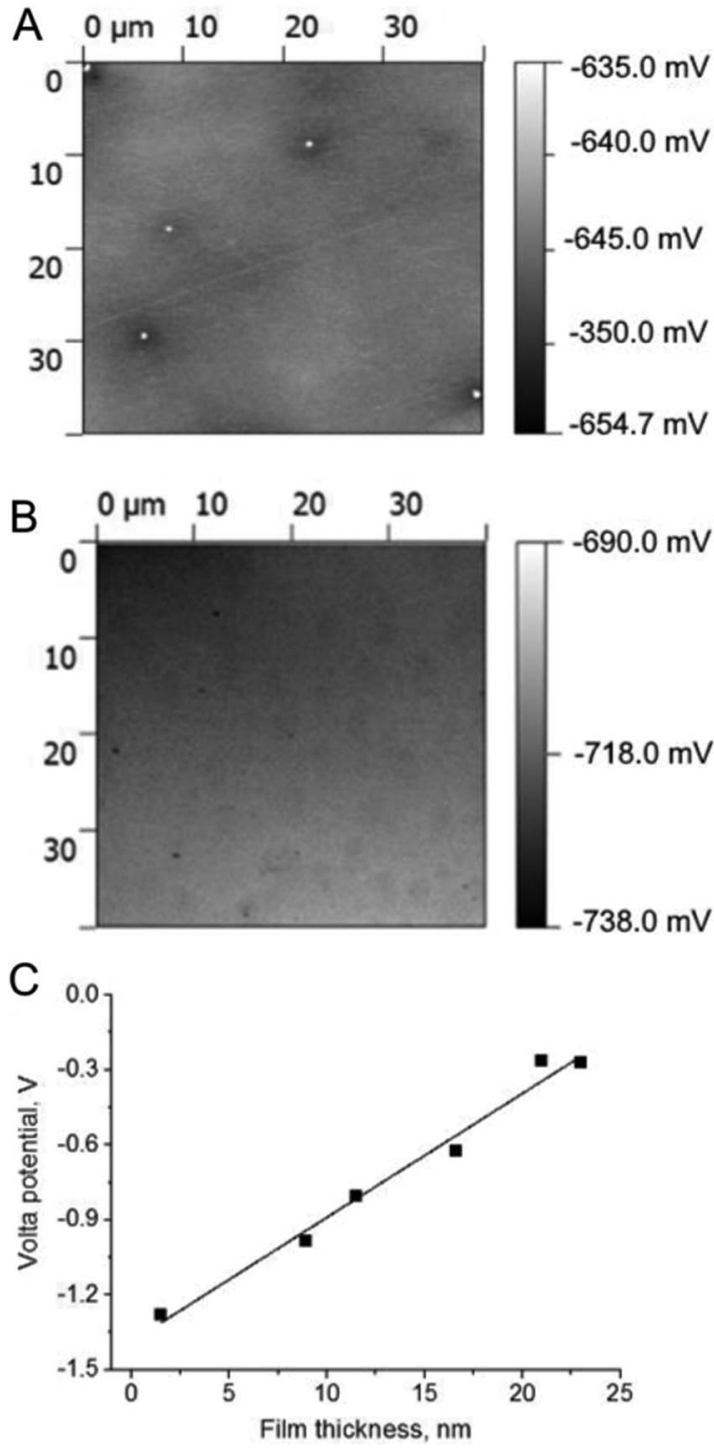

Figure 4. SKPFM images of aluminum samples with oxide thickness of 15 $\mathrm{nm}$ anodized by high-voltage anodization at applied voltage of $1600 \mathrm{~V}$ by potentiostatic $(\mathrm{A})$ and discharge $(\mathrm{B})$ methods. Volta potential difference versus thickness of the alumina films (different number of discharges) prepared by discharge method at an applied voltage of $1600 \mathrm{~V}(\mathrm{C})$.

Considering that the resistance parameter $\beta$ is the same for all the films and very close to the values found for self-discharge of a capacitor $\left(2.2 \times 10^{3} \Omega\right)$, it is possible to fit the second part of the plot using Equation 3 and reveal the parameter $U_{0}$. Estimated values of thickness were found to be in good agreement (less than 5\%) with values in Table I obtained from EIS and TEM measurements.

EIS measurements of the anodized aluminum samples with an oxide thickness of $20 \mathrm{~nm}$ prepared by different methods are displayed in Fig. 5. The impedance values of the specimens prepared by highvoltage potentiostatic anodization (red dash line) are higher than those measured on the pure metal coated only by the native oxide (black solid line), but significantly lower in comparison with those prepared by the discharge method (dash dot green line) and conventional anodization in ammonium pentaborate solution (dot blue line). This last film was prepared for the sake of comparison by galvanostatic followed by potentiostatic anodization in solution of ammonium pentaborate. The advantages of the two-step method of anodization in comparison with pure galvanostatic are described in the literature. ${ }^{10,18,19}$ Alumina films prepared in this way have been well studied and have a dense uniform structure. ${ }^{10,15,18,19}$ According to the data from electron microscopy 


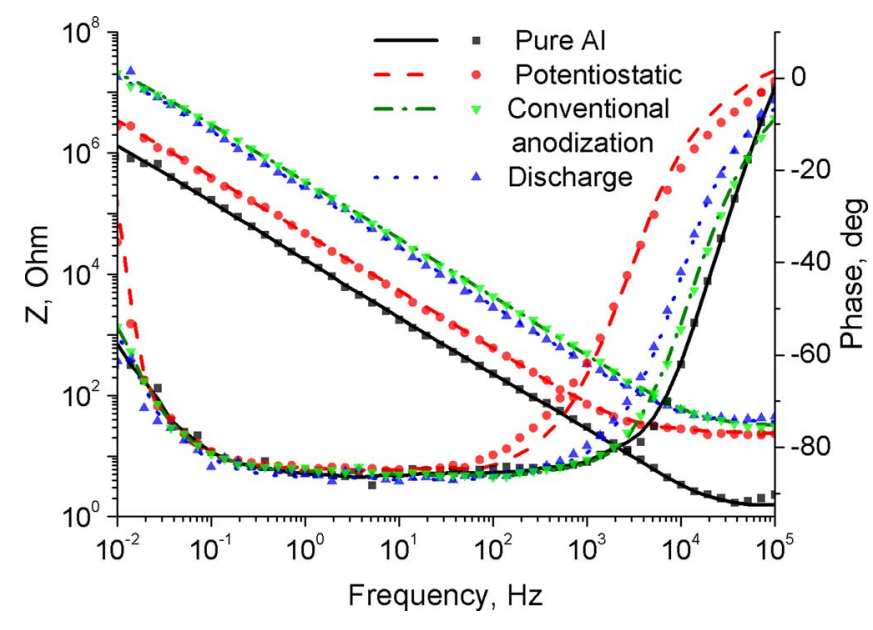

Figure 5. The impedance spectra recorded on as-polished Al with a native oxide film (black solid) and anodized aluminum in different conditions: Al with: $10 \mathrm{~nm}$ thick oxide prepared by potentiostatic method in deinonized water (red dashed line); oxide with thickness of $20 \mathrm{~nm}$ prepared by discharged method in deionized water (blue dotted line); oxide with thickness of 20 $\mathrm{nm}$ prepared by conventional anodization in ammonium pentaborate solution (green dash-dot). Experimental: points; Fitting: lines.

(Figs. 3B, 3D) and SKPFM (Fig. 4B), the topography of the films prepared by the discharge method is similar to those obtained by the conventional method.

The EIS spectra were fitted with a model, that consists of a constant phase element $(\mathrm{CPE})$ in parallel with a resistor $(\mathrm{R})$ corresponding to the oxide film, in series with an additional resistor element, which describes the electrolyte. The physical origin of the CPE has been widely discussed in the literature. ${ }^{21}$ The impedance of the $\mathrm{CPE}, \mathrm{Z}_{\mathrm{CPE}}$, depends on frequency, $\omega$, according to the following equation:

$$
Z_{C P E}=[Q(j \omega) n]^{-1}
$$

where $\mathrm{Q}$ is a parameter numerically equal to the admittance $\left(|\mathrm{Z}|^{-1}\right)$ at $\omega=1 \mathrm{rad} \mathrm{s}^{-1}$ and $n(\leq 1)$ is a power coefficient calculated as the ratio of the measured maximum phase angle and -90 degrees. The fitting of the spectra shows a high goodness $\left(<10^{-6}\right.$ according to the Echem Analyst software) and low error ( $<1 \%$ for all parameters) (Fig. 5). The value of effective capacitance, $\mathrm{C}_{\text {eff }}$, was estimated by assuming a normal time-constant distribution through a surface layer by equation 5 derived by Hirschorn et al.: ${ }^{22}$

$$
C_{e f f}=Q^{1 / n} R^{(1-n) / n}
$$

The capacitances of all films prepared by the discharge method were higher by $5-10 \%$ than for the films prepared by conventional method. Capacitance, $C$, is related to thickness, $d$, by the following equation:

$$
C=\varepsilon \varepsilon_{0} \frac{S}{d}
$$

where $S$ is the surface area and $\varepsilon$ is the dielectric constant of the film and $\varepsilon_{0}$ is the vacuum permittivity $\left(8.854 \times 10^{-12} \mathrm{~F} \cdot \mathrm{m}^{-1}\right)$. Taking into account that the thickness of the samples prepared by both methods is similar $(20 \mathrm{~nm})$ and using Eq. 6 it was found that the aluminum oxide prepared by electrochemical oxidation of $\mathrm{Al}$ in deionized water has a dielectric constant of 9.3-9.9 with a mean value of 9.8. This value is slightly higher than the value obtained for the alumina (9.0) produced by conventional anodization.

\section{Conclusions}

The formation of oxide films on the aluminum surface in deionized water was demonstrated in the current work by several methods: TEM, EIS, SKPFM. Images and properties of the films are in good agreement with those widely presented in literature for different conditions.

Discharge and potentiostatic methods were used to prepare thin oxide films on the surface of aluminum in deionized water. The maximum thickness of the anodic film increased with increasing the applied voltage, but at voltages over $1800 \mathrm{~V}$ oxide film cannot be prepared by either methods due to film breakdown. The maximum thickness of the film was $12 \mathrm{~nm}$ for the potentiostatic method and $26 \mathrm{~nm}$ for the discharge method. The alumina films obtained by the discharge method have also better uniformity in comparison to those prepared by the potentiostatic method. Both films have a dielectric constant comparable to that for the alumina films obtained in conventional electrolytes.

The data here obtained can be used as a reference for better understanding of the properties of anodic films prepared in conventional electrolytes. Further investigation allowing to obtain additional parameters, such as nature of defects, charge carriers concentration, etc., will be pursued.

\section{Acknowledgments}

Financial support of FCT grants PTDC/CTM/72223/2006 and SFRH/BD/78628/2011 are gratefully acknowledged.

\section{References}

1. L. P. H. Jeurgens, W. G. Sloof, F. D. Tichelaar, and E. J. Mittemeijer, Journal of Applied Physics, 92, 1649 (2002).

2. J. Lausmaa, B. Kasemo, H. Mattsson, and H. Odelius, Applied Surface Science, 45, 189 (1990).

3. P. S. Pawar, S. V. Gogawale, D. C. Kothari, A. M. Narsale, P. D. Prabhawalkar, and P. M. Raole, Thin Solid Films, 193, 683 (1990).

4. B. Kasalica, M. Petkovic, I. Belca, S. Stojadinovic, and L. Zekovic, Surf Coat Tech, 203, 3000 (2009).

5. M. Mokaddem, J. Tardelli, K. Ogle, E. Rocca, and P. Volovitch, Electrochemistry Communications, 13, 42 (2011).

6. K. Ozawa and T. Majima, Journal of Applied Physics, 80, 5828 (1996).

7. A. Cigada, M. Cabrini, and P. Pedeferri, J Mater Sci-Mater M, 3, 408 (1992).

8. A. D. Lisenkov, S. K. Poznyak, M. F. Montemor, M. J. Carmezim, M. L. Zheludkevich, and M. G.S. Ferreira, Journal of the Electrochemical Society, 161, D73 (2014).

9. G. T. Rogers, P. H. G. Draper, and S. S. Wood, Electrochimica Acta, 13, 251 (1968).

10. K. A. Yasakau, M. L. Zheludkevich, S. V. Lamaka, and M. G. Ferreira, J Phys Chem $B, 110,5515$ (2006).

11. H. O. Jacobs, H. F. Knapp, S. Muller, and A. Stemmer, Ultramicroscopy, 69, 39 (1997).

12. M. Yasutake, D. Aoki, and M. Fujihira, Thin Solid Films, 273, 279 (1996)

13. B. S. Tanem, G. Svenningsen, and J. Mardalen, Corrosion Science, 47, 1506 (2005).

14. S. K. Poznyak, D. V. Talapin, and A. I. Kulak, Journal of Electroanalytical Chemistry, 579, 299 (2005).

15. A. D. Lisenkov, A. N. Salak, S. K. Poznyak, M. L. Zheludkevich, and M. G. S. Ferreira, Journal of Physical Chemistry C, 115, 18634 (2011).

16. S. K. Poznyak, A. D. Lisenkov, M. G. S. Ferreira, A. I. Kulak, and M. L. Zheludkevich, Electrochimica Acta, 76, 453 (2012).

17. E. Gileadi, Angew Chem Int Ed Engl, 106, 839 (1994)

18. P. Skeldon, M. Skeldon, G. E. Thompson, and G. C. Wood, Philosophical Magazine Part B, 60, 513 (1989).

19. A. Despić and V. P. Parkhutik, Electrochemistry of Aluminum in Aqueous Solutions and Physics of Its Anodic Oxide, in Modern Aspects of Electrochemistry, J. O'M. Bockris, R. E. W., and B. E. Conway ed., 1989, p. 401.

20. D. Landau, J. S. Bell, M. J. Kearsley, L. P. Pitaevskii, E. M. Lifshitz, and J. B. Sykes, Electrodynamics of Continuous Media (2nd edition), Pergamon Press, 1980, 460.

21. P. Zoltowski, Journal of Electroanalytical Chemistry, 443, 149 (1998).

22. B. Hirschorn, M. E. Orazem, B. Tribollet, V. Vivier, I. Frateur, and M. Musiani, Electrochimica Acta, 55, 6218 (2010). 